\title{
STRONGYLS BENZIMIDAZOLE RESISTANCE \\ IN EQUINE FROM ZOO
}

\author{
Lecturer Mihai CERNEA*, PhD \\ Lecturer Cristina CERNEA**, PhD
}

\begin{abstract}
The research in view of establishing the development and the way in which antihelmintical treatment influences epidemiological indexes, was carried out between October 2008 and May 2009 in equine species from zoos.

In the zoo located Targu Mures it was noticed am strongyls intensity of 2300 EPG - 8700 LPG in horses, and 700 EPG - 1400 LPG in ponies. In vitro effectiveness of bemzimidazoles (BZ) being low in both horses and ponies. In the zoo located in Turda the intensity of the strongyl parasitism reached the level of 900 EPG - 2300 LPG in horses and 2400EPG - 2800 LPG in ponies, the effectiveness of the benzimidazoles being low. In the zoo located in Baia Mare the intensity of strongyls infestation was of 900 EPG - 1600 LPG in horses, 1900 EPG - 2600 LPG in ponies, 900 EPG -1500 LPG in donkeys benzimidazoles treatment being proven effective.

Cyathostomum species are considered as having the most significant pathology in equines. Worldwide, anthelmintical treatment, especially in strongylatosis, faces an ever-increasing phenomenon of drug resistance, to phenotiazin, thiabendazole as well as other BZ and ProBZ, in the strongyls population [Moore, 2000]. The lack of success in treatment using drug combinations (piperazin and phenotiazin; triclorfon and phenotiazin; diclorfos and morantel) have spurred the development of new substances to which strongyls have not developed resistance [Lyons and Drudge, 1999]. Tong time treatment with the same substance leads to the development of drug-resistant strongyl population, thus a low effectiveness, below the desired level [Bauer, 1983].
\end{abstract}

Keywords: Strongyls, equine, zoo, Cyathostomum, benzimidazole resistace.

\section{Materials and Methods}

The research carried out in three zoos between October 2008 and May 2009 showed complex yet specific aspects of strongyls infestation, even if the total number of animals was relatively small $(n=12)$. The tests employed were: egg hatch assay - EHA and larval development assay - LDA. The tested molecules were: thiabendazol - TBZ, mebendazol - MBZ, fenbendazol - FBZ and albendazol - ABZ.

\footnotetext{
* University of Agricultural Sciences and Veterinary Medicine Cluj-Napoca, Faculty of Veterinary Medicine, Department of Farmacology, 3-5 Mănăştur Street, 400372 Cluj-Napoca, Romania, e-mail: mscernea@yahoo.com

** University of Agricultural Sciences and Veterinary Medicine. Faculty of Veterinary Medicine, Department of Phisiology, 3-5 Mănăştur Street, 400372 Cluj-Napoca, Romania.
}

Cluj Veterinary Journal, 15(1)/2009, pp. 63-68 


\section{Results and Discussion}

\section{Târgu-Mureş zoo - Jud. Târgu-Mureş}

In this facility there were 5 individuals, 2 horses and 3 ponies which were separately housed. Regarding the level of strongyls infestation it was noticed that in horses was of 2300 EPG - 700 LPG. The ponies showed a lower level of infestation 700 EPG - 1400 LPG (table 1).

Table 1. Level of strongyls infestation and the identified species - Târgu-Mureş zoo

\begin{tabular}{|c|c|c|c|c|c|}
\hline \multirow{2}{*}{ Species } & \multirow{2}{*}{ No. } & \multicolumn{2}{|c|}{ Intensivity } & \multicolumn{2}{c|}{ Identified species (\%) } \\
\cline { 3 - 6 } & & EPG & LPG & Cyathostomum A & Cyathostomum D \\
\hline Horses & 2 & 2300 & 8700 & 80 & 20 \\
\hline Ponies & 3 & 700 & 1400 & 40 & 60 \\
\hline
\end{tabular}

In the past few years anthelmintic treatment in horses was done twice a year, with albendazole and triclorfon. The egg hatch assay done in the horses proved the lowest effectiveness of mebendazole $(\mathrm{Y}=672.90)$, followed by albendazole and fenbendazole (tabel2).

Table 2. The results obtained by using EHA and LDA tests at horses from Târgu-Mureş zoo

\begin{tabular}{|c|c|c|c|c|c|c|c|c|}
\hline & \multicolumn{2}{|c|}{ Thiabendazol } & \multicolumn{2}{|c|}{ Mebendazol } & \multicolumn{2}{|c|}{ Fenbendazol } & \multicolumn{2}{|c|}{ Albendazol } \\
\hline \multicolumn{9}{|c|}{ EHA } \\
\hline \multicolumn{9}{|c|}{ The egg hatching $\%$ on the control samples $=71,11$} \\
\hline \multirow{8}{*}{ 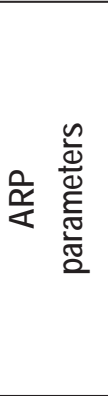 } & a & b & a & b & a & b & a & b \\
\hline & $-387,59$ & 41,49 & 118,06 & 82,60 & 54,14 & 81,90 & 96,39 & 89,30 \\
\hline & \multicolumn{8}{|c|}{ hatching $\%$ at $0,15 \mu \mathrm{g} / \mathrm{ml}$} \\
\hline & \multicolumn{2}{|c|}{$-16,64$} & \multicolumn{2}{|c|}{100,31} & \multicolumn{2}{|c|}{90,02} & \multicolumn{2}{|c|}{103,76} \\
\hline & \multicolumn{8}{|c|}{$\mathrm{LC}_{50}$} \\
\hline & \multicolumn{2}{|c|}{$-0,0219$} & \multicolumn{2}{|c|}{$-0,2761$} & \multicolumn{2}{|c|}{$-0,5893$} & \multicolumn{2}{|c|}{$-0,4077$} \\
\hline & \multicolumn{8}{|c|}{$Y$ maxim } \\
\hline & \multicolumn{2}{|c|}{$-1896,46$} & \multicolumn{2}{|c|}{672,90} & \multicolumn{2}{|c|}{352,6} & \multicolumn{2}{|c|}{571,25} \\
\hline \multicolumn{9}{|c|}{ LDA } \\
\hline \multicolumn{9}{|c|}{ The larval development $\%$ on the control samples $=50,27$} \\
\hline \multirow{6}{*}{ 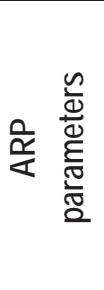 } & \multicolumn{8}{|c|}{ MIC } \\
\hline & \multicolumn{2}{|c|}{0,0269} & \multicolumn{2}{|c|}{0,1330} & \multicolumn{2}{|c|}{0,0269} & \multicolumn{2}{|c|}{0,0682} \\
\hline & $a$ & b & $a$ & b & $a$ & b & $a$ & b \\
\hline & $-311,05$ & 8,37 & $-233,01$ & 31,31 & $-311,05$ & 8,37 & $-242,71$ & 21,56 \\
\hline & \multicolumn{8}{|c|}{$Y$ maxim } \\
\hline & \multicolumn{2}{|c|}{$-1546,88$} & \multicolumn{2}{|c|}{$-1133,74$} & \multicolumn{2}{|c|}{$-1546,88$} & \multicolumn{2}{|c|}{$-1191,99$} \\
\hline
\end{tabular}

The larval development assay showed a negative tendency of the regression curve for all tested substances (table 2). These results showed a high effectiveness of BZ over the strongyls population, but in case of mebendazole and albendazole high levels of third stage larva were observed at high concentrations (MBZ $-0,3125 \mu \mathrm{g} / \mathrm{ml}$; ABZ $-5 \mu \mathrm{g} / \mathrm{ml}$ ). Global analysis of the tow assays highlights the resistant strongyls forms to the usual anthelmintical medication, this being confirmed by the high levels of infestation (8700 LPG). In this case, a change in the anthelmintical medication is recommended, using substances from the tetrahidropirimidin group, or macrocyclic lactones.

A similar situation was noticed in the ponies, egg hatch assays showed a high effectiveness for the tested substances, highest among them was fenbendazol and thiabendazol (Y-1546.88) (table 3). For all substances tested the regression curve showed a negative tendency, thus we can consider 
that strongyls population did not develop resistance to BZ. In case of the larval development assay the result showed that the only effective BZ were mebendazole ( $Y=-581.19)$ and fenbendazole ( $Y=-92.66$ ), for which the regression curve being negative (table 3). For these substances MIC had lowest values, of $0.2019 \mu \mathrm{g} / \mathrm{ml}$, and $1.5224 \mu \mathrm{g} / \mathrm{ml}$. In case of albendazol and thiabendazol third stage larva that developed at a concentration of $0.3125 \mu \mathrm{g} / \mathrm{ml}$ (maximal development percent) and $0.1563 \mu \mathrm{g} /$ $\mathrm{ml}$, these values determining a positive tendency in the regression curve. Statistical interpretation showed negative values for the MIC for these tow substances, which reflects e low effectiveness over the strongyls population. Global analysis of the four tests of therapeutic effectiveness shows a high susceptibility to BZ resistance in the strongyls population.

Table 3. The results obtained by using EHA and LDA tests at ponies from Târgu-Mureş zoo

\begin{tabular}{|c|c|c|c|c|c|c|c|c|}
\hline & \multicolumn{2}{|c|}{ Thiabendazol } & \multicolumn{2}{|c|}{ Mebendazol } & \multicolumn{2}{|c|}{ Fenbendazol } & \multicolumn{2}{|c|}{ Albendazol } \\
\hline \multicolumn{9}{|c|}{ EHA } \\
\hline \multicolumn{9}{|c|}{ The egg hatching $\%$ on the control samples $=53,12$} \\
\hline \multirow{8}{*}{ 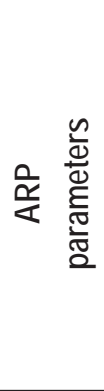 } & a & b & a & b & a & b & a & b \\
\hline & $-33,28$ & 52,59 & 189,37 & 70,84 & 31,92 & 74,90 & 139,26 & 67,92 \\
\hline & \multicolumn{8}{|c|}{ hatching $\%$ at $0,15 \mu \mathrm{g} / \mathrm{ml}$} \\
\hline & \multicolumn{2}{|c|}{47,68} & \multicolumn{2}{|c|}{47,60} & \multicolumn{2}{|c|}{79,69} & \multicolumn{2}{|c|}{88,81} \\
\hline & \multicolumn{8}{|c|}{$\mathrm{LC}_{50}$} \\
\hline & \multicolumn{2}{|c|}{0,0780} & \multicolumn{2}{|c|}{$-0,1100$} & \multicolumn{2}{|c|}{$-0,7803$} & \multicolumn{2}{|c|}{$-0,1287$} \\
\hline & \multicolumn{8}{|c|}{$Y$ maxim } \\
\hline & \multicolumn{2}{|c|}{$-1546,88$} & \multicolumn{2}{|c|}{$-1133,74$} & \multicolumn{2}{|c|}{$-1546,88$} & \multicolumn{2}{|c|}{$-1191,99$} \\
\hline \multicolumn{9}{|c|}{ LDA } \\
\hline \multicolumn{9}{|c|}{ The larval development $\%$ on the control samples $=31,50$} \\
\hline \multirow{6}{*}{ 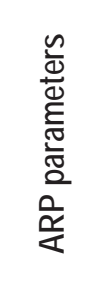 } & \multicolumn{8}{|c|}{ MIC } \\
\hline & \multicolumn{2}{|c|}{$-0,2136$} & \multicolumn{2}{|c|}{0,2019} & \multicolumn{2}{|c|}{1,5224} & \multicolumn{2}{|c|}{$-0,2620$} \\
\hline & a & b & a & b & a & b & a & b \\
\hline & 261,08 & 55,92 & $-121,26$ & 25,11 & $-26,67$ & 40,69 & 177,57 & 46,84 \\
\hline & \multicolumn{8}{|c|}{$Y$ maxim } \\
\hline & \multicolumn{2}{|c|}{1361,32} & \multicolumn{2}{|c|}{$-581,19$} & \multicolumn{2}{|c|}{$-92,66$} & \multicolumn{2}{|c|}{934,69} \\
\hline
\end{tabular}

\section{Turda zoo, jud. Cluj}

In this zoo the equine population was made up of a horse and 3 ponies. Infestation reached a level of 900 OPG and 2300 LPG in case of the horse. The ponies showed a grater infestation level being 2400OPG and 2800LPG (table 4)

Table 4. Level of strongyls infestation and the identified species - Turda zoo

\begin{tabular}{|c|c|c|c|c|c|c|}
\hline \multirow{2}{*}{ Species } & \multirow{2}{*}{ No. } & \multicolumn{2}{|c|}{ Intensivity } & \multicolumn{3}{|c|}{ Identified species (\%) } \\
\cline { 3 - 7 } & & EPG & LPG & Cyathostomum A & Cyathostomum C & Cyathostomum D \\
\hline horse & 1 & 900 & 2300 & 51,3 & 10 & 38,7 \\
\hline ponies & 3 & 2400 & 2800 & 71,19 & - & 28,81 \\
\hline
\end{tabular}

Anthelmintical treatments are done three times a year using albendazole based pharmaceutical products. Statistical interpretation of data obtained through the egg hatch assay showed a very low effectiveness of fenbendazole ( $Y=1273.84$ ) and mebendazole ( $\mathrm{Y}=250.20)$, the overall aspect of the regression curves being influenced by these positive values (table 5). In the larval development assay, even if the regression curves have a negative tendency, high MIC values are noticed, especially in 
fenbendazole $(0,2672 \mu \mathrm{g} / \mathrm{ml})$ and albendazole $(0,1511 \mu \mathrm{g} / \mathrm{ml})$ (table 5). Global analysis of this data shows that the strongyls population is becoming resistant to benzimidazoles and benzimidazole derivatives. To prevent this phenomenon a change in the anthelmintical medication is recommended, using substances from the tetrahidropirimidine group, or macrocyclic lactones [Cernea et al, 2005].

Table 5. The results obtained by using EHA and LDA tests on equines from Turda zoo

\begin{tabular}{|c|c|c|c|c|c|c|c|c|}
\hline & \multicolumn{2}{|c|}{ Thiabendazol } & \multicolumn{2}{|c|}{ Mebendazol } & \multicolumn{2}{|c|}{ Fenbendazol } & \multicolumn{2}{|c|}{ Albendazol } \\
\hline \multicolumn{9}{|c|}{ EHA } \\
\hline \multicolumn{9}{|c|}{ The egg hatching $\%$ on the control samples $=58,33$} \\
\hline \multirow{8}{*}{ 离 } & a & b & a & b & a & b & a & b \\
\hline & $-97,05$ & 41 & 36,43 & 68,05 & 236,41 & 91,79 & 216,66 & 87,90 \\
\hline & \multicolumn{8}{|c|}{ hatching $\%$ at $0,15 \mu \mathrm{g} / \mathrm{ml}$} \\
\hline & \multicolumn{2}{|c|}{26,44} & \multicolumn{2}{|c|}{73,52} & \multicolumn{2}{|c|}{127,25} & \multicolumn{2}{|c|}{120,40} \\
\hline & \multicolumn{8}{|c|}{ LC $_{50}$} \\
\hline & \multicolumn{2}{|c|}{$-0,0926$} & \multicolumn{2}{|c|}{$-0,4955$} & \multicolumn{2}{|c|}{$-0,1768$} & \multicolumn{2}{|c|}{$-0,1749$} \\
\hline & \multicolumn{8}{|c|}{$Y$ maxim } \\
\hline & \multicolumn{2}{|c|}{$-444,25$} & \multicolumn{2}{|c|}{250,20} & \multicolumn{2}{|c|}{1273,84} & \multicolumn{2}{|c|}{1171,20} \\
\hline \multicolumn{9}{|c|}{ LDA } \\
\hline \multicolumn{9}{|c|}{ The larval development $\%$ on the control samples $=62,50 \%$} \\
\hline \multirow{6}{*}{ 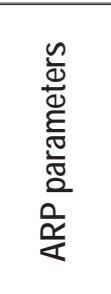 } & \multicolumn{8}{|c|}{ MIC } \\
\hline & \multicolumn{2}{|c|}{0,0269} & \multicolumn{2}{|c|}{0,0269} & \multicolumn{2}{|c|}{0,2677} & \multicolumn{2}{|c|}{0,1511} \\
\hline & $a$ & b & a & b & a & b & a & b \\
\hline & $-386,72$ & 10,41 & $-386,72$ & 10,41 & $-175,10$ & 46,91 & $-243,28$ & 36,79 \\
\hline & \multicolumn{8}{|c|}{$Y$ maxim } \\
\hline & \multicolumn{2}{|c|}{$-1923,19$} & \multicolumn{2}{|c|}{$-1923,19$} & \multicolumn{2}{|c|}{$-828,59$} & \multicolumn{2}{|c|}{$-1179,61$} \\
\hline
\end{tabular}

\section{Baia Mare zoo, jud. Maramureş}

In this zoo the equine population was made up of 3 equine species (horse, pony and donkey) with ages between 7 and 12 years. The 3 animals are housed together in the same enclosure, feed being supplied from producers. The maximum intensity of the strongyls infestation was in the pony in which OPG level reached 1900 and LPG 2600. The horse varied between 900 OPG and 1600 LPG, the donkey showed a similar situation (table 6)

Table 6. Level of strongyls infestation and the identified species - Baia Mare zoo

\begin{tabular}{|l|c|c|c|c|c|c|c|c|}
\hline \multirow{2}{*}{} & \multicolumn{2}{|c|}{ Intensivity } & \multicolumn{7}{c|}{ Identified species (\%) } \\
\cline { 2 - 9 } & \multirow{2}{*}{ EPG } & LPG & \multicolumn{2}{c|}{ Cyathosto-mum } & \multirow{2}{*}{ Gyaloce-phalus } & Poterios-tomum & $\begin{array}{c}\text { Oesopha- } \\
\text { godontus }\end{array}$ & $\begin{array}{c}\text { S. } \\
\text { vulgaris }\end{array}$ \\
\cline { 4 - 9 } & & A & D & & - & - & 16,67 \\
\hline horse & 900 & 1600 & 33,33 & 50,00 & - & 20,01 & - & - \\
\hline pony & 1900 & 2600 & 36,66 & 30,00 & 13,33 & 14,28 & 11,92 & - \\
\hline donkey & 900 & 1500 & 33,30 & 40,47 & - & & & \\
\hline
\end{tabular}

The equines Baia-Mare Zoo are dewormed annually with ABZ or FBZ based pharmaceutical products, the last treatment was applied using FBZ in April 2005.

Through analysis of EHA it was noticed that the percentage of hatching at the concentration of $0.15 \mu \mathrm{g} / \mathrm{ml}$ was null in all substances, except ABZ were it reached $10 \%$, but below the $50 \%$ that indicates resistance (table 7). From a statistical point of view the obtained values were $-15.3 \%$ for FBZ, $-14.41 \%$ for MBZ and 4.61\% for ABZ, which determined a direct correlation with the negative values obtained in the $\mathrm{LC}_{50}$. 
Table 7. The results obtained by using EHA and LDA tests on equines from Baia Mare zoo

\begin{tabular}{|c|c|c|c|c|c|c|c|c|}
\hline & \multicolumn{2}{|c|}{ Thiabendazol } & \multicolumn{2}{|c|}{ Mebendazol } & \multicolumn{2}{|c|}{ Fenbendazol } & \multicolumn{2}{|c|}{ Albendazol } \\
\hline \multicolumn{9}{|c|}{ EHA } \\
\hline \multicolumn{9}{|c|}{ The egg hatching $\%$ on the control samples $=38,98$} \\
\hline \multirow{8}{*}{ 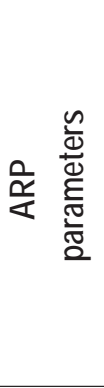 } & a & b & a & b & a & b & a & b \\
\hline & $-247,55$ & 14,97 & $-209,66$ & 17,03 & $-195,81$ & 14,23 & $-171,63$ & 30,36 \\
\hline & \multicolumn{8}{|c|}{ hatching $\%$ at $0,15 \mu \mathrm{g} / \mathrm{ml}$} \\
\hline & \multicolumn{2}{|c|}{$-22,15$} & \multicolumn{2}{|c|}{$-14,41$} & \multicolumn{2}{|c|}{$-15,13$} & \multicolumn{2}{|c|}{4,61} \\
\hline & \multicolumn{8}{|c|}{$\mathrm{LC}_{50}$} \\
\hline & \multicolumn{2}{|c|}{$-0,1414$} & \multicolumn{2}{|c|}{$-0,1572$} & \multicolumn{2}{|c|}{$-0,1826$} & \multicolumn{2}{|c|}{$-0,1144$} \\
\hline & \multicolumn{8}{|c|}{$Y$ maxim } \\
\hline & \multicolumn{2}{|c|}{$-1222,78$} & \multicolumn{2}{|c|}{$-1031,27$} & \multicolumn{2}{|c|}{$-964,82$} & \multicolumn{2}{|c|}{$-827,79$} \\
\hline \multicolumn{9}{|c|}{ LDA } \\
\hline \multicolumn{9}{|c|}{ The larval development $\%$ on the control samples $=53,82$} \\
\hline \multirow{6}{*}{ 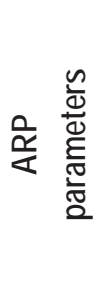 } & \multicolumn{8}{|c|}{ MIC } \\
\hline & \multicolumn{2}{|c|}{0,1980} & \multicolumn{2}{|c|}{0,1762} & \multicolumn{2}{|c|}{0,6959} & \multicolumn{2}{|c|}{0,1497} \\
\hline & a & b & a & b & a & b & a & b \\
\hline & $-171,85$ & 34,10 & $-216,01$ & 38,10 & $-58,49$ & 40,75 & $-250,83$ & 37,64 \\
\hline & \multicolumn{8}{|c|}{$Y$ maxim } \\
\hline & \multicolumn{2}{|c|}{$-825,15$} & \multicolumn{2}{|c|}{$-1041,95$} & \multicolumn{2}{|c|}{$-251,70$} & \multicolumn{2}{|c|}{$-1216,51$} \\
\hline
\end{tabular}

Analysis of the risk degree regarding the manifestation of resistance to BZ in the strongyls population from these equines showed negative tendencies in all tested substances. The lowest risk degree was found for MBZ ( $Y=-1031.27$, followed by FBZ (Y=-964.82) and ABZ ( $Y=-827.79)$.

Thou in this facility the risk of infestation is not reduced; it is considered that applying treatment correlating with isolation of this group from the sources of massive contamination determines weak pressure for the adaptation of the strongyls to the usual medication. To further reduce the degree of strongyls infestation in equines requires a therapeutic strategy that includes a minimum of 2 annual treatments and for the prevention of resistance the treatment alternating substances from different pharmacological groups.

In case of LDA the first third stage larva appeared at a concentration of $0.0781 \mu \mathrm{g} / \mathrm{ml}$ for TBZ and ABZ, and $0.0391 \mu \mathrm{g} / \mathrm{ml}$ for MBZ and FBZ (table 7). Analysis of the data determined MIC values of $0.1980 \mu \mathrm{g} / \mathrm{ml}$ for TBZ, $0.1762 \mu \mathrm{g} / \mathrm{ml}$ for MBZ, $0.6959 \mu \mathrm{g} / \mathrm{ml}$ for FBZ and $0.1497 \mu \mathrm{g} / \mathrm{ml}$ for ABZ. Even if MIC has rather high values, mapping the regression curve has a negative tendency, which is correlated with good sensitivity of the strongyls population to the tested medication. The regression curve is similar to that obtained in the EHA, which confirms the lack of resistance of the strongyls to BZ derivatives.

\section{Conclusions}

In the equine population from Tg Mures Zoo, it has been noticed the intensity of strongylidosis infestation as being 2300 OPG - 8700 LPG in horses, and 700 OPG - 1400 LPG in ponies; In vitro effectiveness of BZ being low in both species.

In the equine population from Turda Zoo, it has been noticed the intensity of strongylidosis infestation as being 900 OPG - 2300 LPG in horses and 2400 OPG - 2800 LPG in ponies; In vitro effectiveness of BZ being low in both species. 
In the equine population from Baia-Mare Zoo, it has been noticed the intensity of strongylidosis infestation as being 900 OPG - 160000 LPG in horses and 1900 OPG - 2600 LPG in ponies and 900 OPG - 1500 LPG in donkeys; In vitro effectiveness of BZ being good in all species

\section{References}

1. Bauer C. [1983]. Anthehelmintika resistence problembeschreibung und in vitro unterschungen - Inaug. Diss. Tierarylitl., Hoschschule, Hannover, 422.

2. Cernea M., Cozma V., Cernea C., Mărculescu A., [2005]. Researches about Egg Hatch Assay for the detection of antihelmintic bezimidazoles resistance, in horse strongyles. $5^{\text {th }}$ International conference of PhD students, University of Miskolc, Hungary 14-20 August 2005.

3. Lloyds., Soulsby E.J.L., [1998]. Is anthelmintic resistance inevitable: back to basics? Equine Vet. J., 30 (4), 280-283.

4. Lyons E.S., Drudge T.J., [1999]. Historical perspective of cyathostomes: prevalence, tratment and control programs. Vet. Parasitol., 85 (2/3); 95-225.

5. Moore, J.N., [2000]. Controlling Equine Cyathostomes. Equine Forum, 391-393. 